\title{
El espacio en la instalación sonora*
}

SPACE IN SOUND INSTALLATION

O ESPAÇO NA INSTALAÇÃO SONORA

\section{Carolina Ortiz Cerón**}

Cuadernos de Música, Artes Visuales y Artes Escénicas

/ Volumen 14 - Número 1 / Enero - Junio de 2019

/ ISSN 1794-6670 / Bogotá, D.C., Colombia / pp. 27-44

Fecha de recepción: 9 de abril de 2018

Fecha de aceptación: 16 de julio de 2018

Disponible en línea: 28 de diciembre de 2018

doi10.11144/javeriana.mavae14-1.eeen

* Artículo de reflexión.

* * Artista sonora. Maestra en Música con especialidad en ingeniería de sonido por la Pontificia Universidad Javeriana, magíster en Ciencias y Tecnologías de Artes con especialidad en música e informática musical de la Université Paris 8 y doctora en Ciencias del Arte con especialidad en música y artes sonoras por la Université Paris 1 Panthéon-Sorbonne. ORCID: 0000-0003-1314-1382

\section{Cómo citar:}

Ortiz Cerón, Carolina. 2018. "El espacio en la instalación sonora." Cuadernos de Música, Artes Visuales y Artes Escénicas 14 (1): 27-44. http://doi10.11144/javeriana.mavae14-1.eeen 


\section{Resumen}

La intención de este artículo es exponer el espacio como una de las principales preocupaciones artísticas en la instalación sonora desde distintos puntos de vista (artístico, estético y filosófico). Se toma como base de reflexión el pensamiento espacial de la obra filosófica Esferas, de Peter Sloterdijk, cuyo planteamiento fundamental radica en que la vida es una cuestión de forma, que cualquier espacio imaginado y creado por la humanidad manifiesta una manera de hacer y de ser, y que es en ese lugar donde se puede comprender la esencia del hombre. Se analizan entonces obras de diversos artistas cuyo trabajo se ha desarrollado en gran medida bajo la forma de esta práctica, con el fin de tratar la experiencia del espacio desde la creación sonora. Entre ellos están Max Neuhaus, Robin Minard y Céleste Boursier-Mougenot. Finalmente, se entreteje una conexión entre las obras analizadas y varias cualidades del pensamiento espacial de Sloterdijk para exponerlas en tanto espacios de creación que dejan entrever una manera de relacionarse con el entorno por medio de lo que se escucha. Qué se oye y cómo se lo comparte son preguntas innatas a la experimentación de esta forma artística, de ahí la importancia de la inmersión, la escucha, el recorrido. Bajo esta perspectiva, las obras analizadas son comprendidas como territorios que interrogan artística y estéticamente la escucha, actividad cuyo dinamismo transforma, interroga, redime los espacios de vida.

Palabras clave: instalación sonora; inmersión; territorio de escucha; fonótopo; fonoesfera.

\section{Abstract}

The purpose of this article is to expose the space as one of the main artistic concerns in the sound installation from different points of view (artistic, aesthetic and philosophical). The spatial thought of the philosophical work Esferas, by Peter Sloterdijk, is taken as a basis for reflection, whose fundamental proposal is that life is a question of form, that any space imagined and created by humanity manifests a way of doing and being, and it is in that place where the essence of mankind can be understood. The works of diverse artists, whose work has been developed to a large extent in the form of this practice, are analyzed in order to treat the experience of space from the sound creation. Among them are Max Neuhaus, Robin Minard and Céleste Boursier-Mougenot. Finally, a connection is interwoven between the works analyzed and various qualities of Sloterdijk's spatial thinking to expose them as spaces of creation that reveal a way of relating to the environment through what is heard. What is heard and how it is shared are innate questions to the experimentation of this artistic form, hence the importance of the immersion, the listening, the journey. From this point of view, the analyzed works are understood as territories that interrogate artistic and aesthetic listening, an activity with a dynamism that transforms, interrogates and redeems the spaces of life.

Keywords: sound installation; immersion;

listening territory; phonotope; phonosphere.

\section{Resumo}

A intenção deste artigo é expor o espaço como uma das principais preocupações artísticas na instalação sonora desde diferentes pontos de vista (artístico, estético e filosófico). Toma-se como base de reflexão o pensamento espacial da obra filosófica Esferas, de Peter Sloterdijk, cuja abordagem fundamental radica em que a vida é uma questão de forma, que qualquer espaço imaginado e criado pela humanidade manifesta uma maneira de fazer e de ser, e que é nesse lugar onde se pode compreender a essência do homem. São analisadas então, obras de diversos artistas cujo trabalho foi desenvolvido em grande parte sob a forma desta prática, com o fim de tratar a experiência do espaço a partir da criação sonora. Entre estes estão Max Neuhaus, Robin Minard e Céleste Boursier-Mougenot. Finalmente, se entrelaça uma conexão entre as obras analisadas e várias qualidades do pensamento espacial de Sloterdijk para expô-las em tantos espaços de criação que permitem entrever uma maneira de relacionar-se com o entorno por meio do que se ouve. O que se ouve e como compartilhá-lo são preguntas inatas à experimentação desta forma artística, daí a importância da imersão, a escuta, o percurso sob esta perspectiva, as obras analisadas são compreendidas como territórios que interrogam artística e esteticamente a escuta, atividade cujo dinamismo transforma, interroga, redime os espaços de vida.

Palavras-chave: instalação sonora; imersão; território de escuta; fonotipo; fonosfera. 


\section{EL ESPACIO EN LA INSTALACIÓN SONORA}

La instalación artística refleja explícitamente una preocupación sobre el espacio, preocupación filosófica que, según Peter Sloterdijk, es clave en el pensamiento de la sociedad contemporánea. Según su teoría, plasmada en la obra Esferas, el espacio constituye una explicación del habitar humano, pues implica hacerse a un lugar que revela una forma de ser. Esferas se despliega bajo la pregunta dónde esta el hombre, ramificándose a sí mismo en diversas cuestiones como en qué espacio se sumerge, cómo lo construye y cómo lo comparte. La experiencia del espacio está en el centro del cuestionamiento de Sloterdijk para poder comprender a la humanidad en sus distintas manifestaciones de vida, pues la existencia está intrínsecamente relacionada con la creación de esferas que cobijan, protegen y suplen las necesidades básicas para poder ser. Esferas, Globos, Burbujas (títulos correspondientes a los tres tomos que comprenden esta obra, Esferas I, // y I/I), son imágenes que muestran, como bien lo resume Adolfo Vásquez Rocca sobre Peter Sloterdijk, un pensamiento en el que "la vida es un asunto preeminentemente de forma" $(2008,180)$.

La insistencia en la experiencia del espacio reside en la observación de una sociedad que, a pesar de la globalización económica y tecnológica, habita en espacios que reflejan a su vez una humanidad individualizada, preocupada por la experiencia de lo inmediato y en habitar espacios interrelacionales de tránsito, conexión y transformación que no tienen núcleo común o entorno estable. De ahí que se proponga como imagen representativa de la sociedad contemporánea: burbujas que componen espumas en constante efervescencia.

Según la visión de Sloterdijk,

la civilización altamente tecnológica, el estado de bienestar, el mercado mundial, la esfera de los media: todos esos grandes proyectos quieren imitar en una época descascarada la imaginaria seguridad de esferas que se ha vuelto imposible; ahora se tienen que procurar redes y pólizas de seguros, ellas han de ocupar el lugar de los caparazones celestes; la telecomunicación debe imitar a lo envolvente. El cuerpo de la humanidad quiere procurarse un nuevo estado de inmunidad dentro de una piel electrónico-mediática. (Vásquez 2008, 28)

La imagen que resume lo anterior es la de un mundo poliesférico y espumoso en el que un centro único para la humanidad no existe. Una sociedad descascarada se refiere a una humanidad sin esfera celeste que la haga sentir cobijada, entre muchas razones, por saber que la Tierra es solo un pequeño grano de arena en un vasto universo al que no se le conoce bien y no se sabe dónde termina. La visión panóptica del mundo de siglos anteriores se desvanece ante la actual sociedad. Según esta perspectiva, Sloterdijk señala, entonces, que "la búsqueda del donde es más sensata que nunca: porque se pregunta sobre el lugar que los hombres crean para saber en qué pueden aparecer como eso que ellos son" (Sloterdijk 1987, citado por Regnauld 2011).

La experiencia del espacio es igualmente la base del análisis del cual parte este texto para hablar de la instalación sonora, práctica que es antes que nada una experiencia de un espacio imaginado por un artista y que se comparte primordialmente por medio de la escucha. En tanto esfera acústica, la instalación sonora interroga la escucha humana porque es una actividad inmersiva, involucra un cuerpo resonante y activo que manifiesta conscientemente el 
deseo de estar inmerso en un espacio sonoro. Sumergirse en una instalación es dejarse atravesar por sus sonoridades, es admitir la obra como una campana acústica contenedora que exalta o transforma las cualidades del lugar. Tal como lo plantea Sloterdijk, la audición es seren-el sonido. En este sentido, uno es-en-el sonido cuando se está alojado en la escucha de una instalación sonora. La escucha revela la experiencia del espacio y expone implícitamente los elementos fundamentales de la práctica artística: sonido, oyente, espacio. Por otro lado, las instalaciones sonoras podrían asociarse a esas formas espaciales espumosas vaporosas, formas artísticas que invitan al visitante a sumergirse en una experiencia auditiva efímera.

La intención de este trabajo es, por tanto, relacionar el pensamiento espacial de Sloterdijk con la forma artística de la instalación sonora con el fin de develar, desde distintos puntos de vista -artístico, estético y filosófico- el espacio como una de sus principales preocupaciones artísticas. A partir de este ejercicio, la idea es igualmente dejar entrever otras inquietudes acerca de la experimentación con el sonido.

\section{TERRITORIOS DE ESCUCHA: FRONTERAS PERMEABLES}

Diversas manifestaciones artísticas y culturales evidencian la cuestión del espacio como reflejo de una forma de pensamiento. Un ejemplo es la arquitectura (gran representante de la configuración del mundo y arte que le da forma al habitar), que se dedica a diseñar estructuras arquitectónicas que expresan la idea de espacio interior, espacio en el cual la persona se pueda sentir inmersa, contenida y segura de que este le proporcione todas las facilidades para permanecer y ser en ese espacio. De hecho, distintas dimensiones autorreferenciales del hombre son expuestas por la arquitectura. Foucault (2009) lo señala en su conferencia radial Heteropías, afirmando que la humanidad edifica incluso espacios otros que quedan por fuera de la cotidianidad, pero que materializan cuestiones esenciales, como la muerte, la vejez, la locura y la memoria. Bajo esta perspectiva, ser y pensarse en el mundo es hacerse a un espacio ligado a la idea del estar retenido y vivir en una especie de habitáculo.

La instalación artística es otra manifestación de ese pensamiento espacial, pues se relaciona con la creación de un espacio cuidadosamente diseñado y acondicionado por luces, parlantes, máquinas, pantallas, proyectores, cables, con el fin de alojar en su interior una idea y al mismo tiempo al público; es una práctica que artificialmente acondiciona un espacio para construir otro que se vuelve vivencial en el momento en que es morado (al menos así lo es para la instalación sonora en la que "solo hay mundo o 'materias' en la medida en que se está suspendido o inmerso en el espacio auditivo" (Sloterdijk 2001, 287). Por eso, en una gran mayoría de instalaciones, el público es invitado a alojarse al interior de ellas, pues sin este acto las obras no terminan de realizarse. Las obras son porque se habitan y cuando se habitan. De ahí que puedan ser comprendidas como habitáculos que representan artísticamente un mundo donde el tiempo, el espacio y lo estético se encuentran para modelar una situación inmersiva.

El invitar al visitante a alojarse o instalarse en esta práctica artística está asociado a varias actividades, como recorrer el espacio, sentarse, interactuar y jugar con distintos elementos (si es el caso), para darse a la experiencia de la obra. Por otro lado, esta invitación es una manera de cuestionar el acto mismo de alojarse, pues el visitante, sumergido en la experiencia de la obra está expuesto a las miradas de los que están por fuera de la instalación. Así, se pone en el centro de observación la experiencia misma del visitante. 
Por otro lado, esta práctica incita a la travesía y a la exploración del espacio por la naturaleza misma del sonido y de la escucha: indagadora, inquieta y curiosa. El dirigir la escucha atentamente hacia lo ofrecido por la instalación es antes que nada alojarse en la escucha, sumergirse en ese espacio íntimo de la escucha que ante la mirada y la razón de los demás visitantes y observadores es misteriosa y difícil de descifrar. La pregunta de dónde estamos cuando escuchamos una obra sonora es pertinente, en especial porque lo que es tangible en el centro de observación de una instalación sonora es en primera medida el modo de exploración auditiva de cada visitante. Aun así, esta actividad a la vista de los demás no revela demasiado sobre la experiencia misma de la instalación, porque, como lo señala Sloterdijk, "es una conducta inherente que se manifiesta durante su ensimismamiento" $(2001,288)$. A lo sumo, ver a otros visitantes gozarse la dimensión sonora de una instalación exterioriza la necesidad humana de crear esferas acústicas humanamente personalizadas, autocomplacientes, esferas imaginadas y compartidas por los artistas a todo aquel visitante dispuesto a sumergirse en ellas.

La instalación sonora está igualmente asociada al territorio porque la escucha implícitamente relaciona al oyente con una situación en un lugar. Para muchos artistas, esa relación con el territorio pasa muchas veces por la experimentación de la plasticidad del sonido y la del espacio arquitectónico, pues ambos elementos se transforman mutuamente ante el oyente, cambiando las impresiones del lugar. Tal como lo enuncia Szendy,

oímos cosas a través del espacio, por medio del espacio. El espacio no es un fondo neutral para oír; el oír ya siempre está implicado en el espacio. El sonido de la arquitectura no es, o al menos no solo es, el sonido de las cosas, de los elementos de construcción. Es más -es también- el sonido de la distancia o de la diferencia entre las cosas. Es el sonido de su espaciamiento. El sonido de la diferencia entre sonidos. O más bien: el sonido del espaciamiento de los sonidos. $(2015,59)$

Para otros artistas, se trata más de cuestionar el contexto de esos lugares por la presencia y cohabitación de obras sonoras en los espacios de vida de la gente. Varios son los artistas que han explorado de distinta manera la relación sonido-arquitectura y la magnifican como Robin Minard, Alvin Lucier, Bill Fontana y Max Neuhaus, entre otros.

Una gran parte de la obra de Max Neuhaus consiste en transformar poéticamente con sus composiciones sonoras la percepción de ciertos espacios, preferiblemente públicos (un rincón de una plaza, un parque, un corredor). Los lugares, tal como llamó a sus trabajos instalativos, tienen algo de sorpresivo, ya que la realidad del lugar se ve transformada impredeciblemente, si estos ocurren por fuera de los espacios de galerías y museos. La obra Times Square (1977-1992, reinstalada en 2002 hasta hoy en Nueva York) es un buen ejemplo de ello, pues Neuhaus escoge como lugar para la instalación un andén ubicado entre las callee 45 y 46 de Manhattan, constituido de rejas metálicas que hacen parte del sistema de ventilación del metro. Se trata de un lugar de flujo de peatones donde la prisa, la cacofonía y el no permanecer lo caracterizan. Es un pasaje acústicamente denso, invasivo, incluso indeseable que, además, no incita a permanecer porque las rejas metálicas, que dejan entrever un vacío que no se sabe qué tan profundo es, provocan que muchos peatones no caminen por encima de ellas. 
En efecto, la escogencia del lugar es insólita, porque sus condiciones hacen pensar que es improbable la presencia de una instalación sonora, incluso porque todo el armazón tecnológico de difusión del sonido se encuentra escondido en los túneles de aireación del metro. De hecho, es una de las razones por las cuales el hallazgo de la obra ocurre sorpresivamente para los peatones, pues ningún elemento visual la pone en evidencia.

La intención de Neuhaus en esta obra radica en cuestionar el espacio mismo, su uso y la manera de lidiar con la situación sonora del lugar. Se puede evidenciarlo comprendiendo cómo esta preocupación implicó unas condiciones para la composición sonora, pues se tuvo que tener en cuenta el aspecto acústico y sonoro del lugar con el fin de asegurar la existencia de la obra (figura 1).

La primera condición fue componer cuatro sonoridades capaces de poner en vibración el volumen de aire del túnel con el fin de producir una sumatoria de sonidos que parecieran propios del lugar. Para esto, se hizo previamente un estudio de la acústica del túnel subterráneo para saber a qué frecuencia resonaba el lugar y así componer en esas frecuencias.

Asimismo, con la idea de construir un espacio sonoro que diera la impresión de que se trataba de "un muro invisible" que nacía justamente del túnel, se construyó un parlante de $1 \mathrm{~m} \times 2 \mathrm{~m}$ con forma de trompa, el cual no apunta hacia las rejillas como uno podría creer, sino hacia el lugar preciso en el que las sonoridades creadas pongan en vibración el espacio.

Times Square se compuso también bajo la idea de jugar ambiguamente con la percepción de la obra. El resultado es entonces una instalación sonora que está presente y disponible para ser escuchada, y al mismo tiempo, que es lo suficientemente discreta para mimetizarse con el entorno sonoro. Así lo define Neuhaus:

La obra es un muro sonoro invisible y discreto en la extremidad norte de la isla. Su sonoridad, una textura rica en armónicos que recuerdan la resonancia del sonido de las campanas, es una imposibilidad en ese contexto. Aun así, muchos de los que pasan pueden rechazarla atribuyéndola a un sonido inusual de las máquinas subterráneas. ${ }^{1}(1995,43)$

Este testimonio deja entrever varias cosas importantes del trabajo instalativo. El primer aspecto tiene que ver con el sonido pensado como frontera, pues su presencia interroga el lugar y el cuerpo del oyente que suele transitar ese espacio y que de repente cambia su ritmo de andar para escuchar la obra. La arquitectura del lugar también es cuestionada por la nueva actividad que sugiere la obra, un lugar de escucha artística. El segundo aspecto se refiere a que esta obra ejemplifica la cuestión de la escucha como un territorio que permite al oyente abrirse a una situación y, al mismo tiempo, protegerse en las sonoridades que desea. Times Square se construye bajo otra manera de pensar el territorio de escucha que ella es por esa dualidad en la que oscila (estar presente en tanto intervención artística y, a la vez, mimetizarse con el paisaje urbano). En este territorio de escucha, no es necesario propiciar un silencio absoluto y realizarse en un espacio aislado de la actividad cotidiana de la gente como lo exige un concierto de música convencional. Está igualmente por fuera de toda posibilidad invitar al oyente a un espacio rodeado de parlantes para sentirse inmerso. Este territorio de escucha puede comprenderse mejor si se pregunta, tal como lo hace Szendy $(2001,16)$ en relación con la música y el oyente: ¿Qué lugar asigna una instalación sonora al oyente? ¿Cómo exige la obra que se escuche? ¿Qué medios se utilizan en una obra para componer una escucha? Estas preguntas revelan una preocupación por la escucha como 
objeto de construcción y de cuestionamiento artístico, de ahí que Szendy hable de componer una escucha. Esta instalación, por ejemplo, le da la bienvenida a una escucha distraída y, al mismo tiempo, curiosa. De hecho, ubicar la instalación en un espacio sonoramente cacofónico es una primera estrategia de composición de la escucha, pues se enmascara la obra exigiendo, por tanto, al oyente una escucha mucho más activa en relación con el entorno sonoro. Tal como ha sido compuesta la escucha de esta instalación, Max Neuhaus cuestiona las fronteras de ese territorio de escucha imaginado y las del paisaje sonoro circundante, pues el peatón se encuentra ante un espacio sonoro permeable y dinámico que, según la atención que desee darle, se revela de manera diferente.

Neuhaus juega, igualmente, con la incertidumbre que provoca la escucha de un sonido que no se sabe qué lo produce (factor que hace parte del proceso de composición de la escucha de la obra, pues ese terreno no está solo definido por lo acústico, sino por su relación con lo visual). Esta percepción auditiva carente de imágenes interroga el entorno, pues, en ausencia de la fuente del sonido, se pierde una conexión inmediata con el lugar. De hecho, dar la impresión de que sonidos de campanas emergen del suelo es una manera de interrogar al transeúnte desprevenido y jugar con su inconsciente colectivo auditivo (¿por qué suenan campanas abajo de mis pies?, ¿acaso ha sido una ilusión auditiva?). Esto es lo que más le interesa provocar a Neuhaus en sus instalaciones: "Me gusta esa contradicción que representa el hecho de ubicar una obra compuesta exclusivamente de sonidos en un contexto visual, porque crea un fenómeno de desplazamiento que nos obliga a cuestionarnos nuevamente; eso es un aspecto de lo que significa ser un artista: llevar a pensar de nuevo las cosas" (Bosseur 1992, 151) (figura 1).

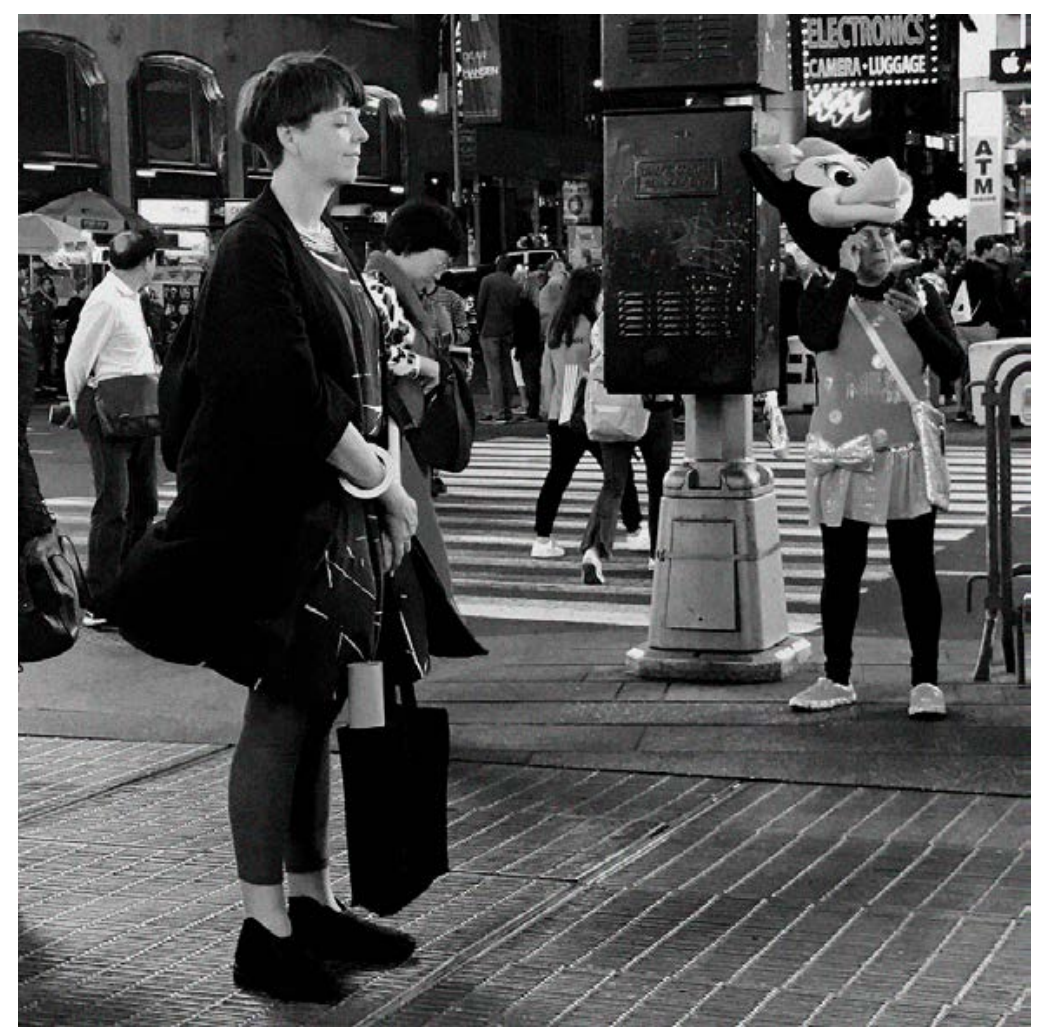

Figura 1. Times Square, Max Neuhaus, 1977-hoy

Listening to Max Neuhaus's Time Square, 2017. Lynda Roberts. Fuente: Roberts (2017) 
Times Square en tanto territorio de escucha demuestra la capacidad que tiene el sonido de interrogar el contexto social, temporal y espacial de un lugar y definirlo artísticamente de otra manera. Vale aclarar que ese territorio no es exclusivamente sonoro, lo visual también es interrogado, basta con ver a diferentes transeúntes merodear, sentarse, acostarse o acuclillarse sobre las rejas. Son acciones que evidencian un cambio en el uso de ese espacio, con la precisión de que, a la vez, no impiden la continuidad de las funciones del andén. Esta instalación señala y cuestiona el contexto y la arquitectura misma del lugar por esa doble situación que se desarrolla. Ya no se trata solo de un espacio de paso, sino de un espacio dentro de otro espacio, cual heterotopía de niño, en la que todo lo que tiene a la vista es transformado por la imaginación para crear un lugar ficticio que es invisible para los que no están inmersos en su universo.

Una prueba del poder tangible de transformación de la instalación ha sido que se ha convertido en un elemento distintivo del Times Square; incluso, en el sitio web de Times Square, estuvo activo por un tiempo un blog en el que se compartían impresiones sobre la instalación. Aquí un testimonio de un caminante y vecino del barrio:

Después de haber experimentado Times Square, Times Square mismo cambió. Hay un secreto allí, un área pequeña en una isla peatonal que tiene el poder de remover la sensación del entorno saturado de la ciudad al caminante. Times Square es un espacio pacífico y privado en el lugar más público de los lugares públicos. (Neuhaus 1999)

La presencia de la obra cuestiona justamente las características del lugar, pues este se convierte en un recinto de observación, de escucha consciente y no escapista, como lo puede ser el paso de los peatones. El lugar es potencialmente un territorio de escucha acogedor porque enmascara la cacofonía de la plaza con sonidos sutiles y relajantes. Si el lugar parece convertirse en un espacio privado y secreto, según el testimonio, puede ser por la naturaleza misma del territorio sonoro creado, pues es discreto y se mimetiza con el paisaje sonoro urbano en el que yace. Da la impresión de que la obra está escondida esperando a que alguien la encuentre. Descubrirla parece convertirla en una experiencia del orden de lo privado, simplemente porque, como lo enuncia Szendy, "lo audible como tal es frágil y puntual como una burbuja, y es justamente por eso que el oído es siempre el teatro de un querer-tener, de un deseo notablemente intenso e insistente de guardia, posesión o dominio $(2015,30)$. Aun así, el "secreto" se revela por la propia corporalidad del oyente. Su cuerpo expone lo oculto a un público desconocido. De hecho, lo que revela la instalación a la vista de los demás es al espía que hay en cada uno de los peatones, porque "el espionaje es una postura fundamental de la escucha" (Peter Szendy citado en Wuillème 2002).

Otra idea que involucra pensar la instalación sonora como un territorio de escucha es que para Neuhaus es importante definir el recorrido de ese lugar desde la composición misma, por eso las cuatro sonoridades distintivas de la obra parecen yacer en distintos puntos del pasaje peatonal. Aquí recorrer significa descubrir la plasticidad de la obra, pues en el caminar es que se pueden percibir sutilmente sus variaciones tímbricas. Esto evidencia un fuerte interés en crear un territorio de escucha que se descubre en el andar y en proponer una composición que se piensa espacial y no temporalmente. Lo deja muy claro en su manera de describir las instalaciones: 
No son una sucesión de eventos de sonido en el tiempo. En la música, el sonido adquiere significado solo a medida que progresa en el tiempo, a medida que los eventos sonoros se desarrollan en el tiempo. En cambio, aquí tenemos bloques de texturas de sonido constantes, un sonido continuum que no cambia. Es el oyente quien los pone en su propio tiempo. (Neuhaus 1998)

Se trata de una concepción sonora en la que no hay principio, ni final. El oyente puede entrar y salir de la obra cuando lo desee. La temporalidad está más asociada con la inmersión, es decir, con la experiencia del oyente y las impresiones que la obra pueda dejar en la memoria.

El territorio de escucha de esta instalación es permanente, a pesar de su constante vaivén entre el mimetizarse con el paisaje sonoro y revelarse impredeciblemente a los peatones. Es un territorio que, además, cuenta con el azar de una escucha distraída pero curiosa, que le apuesta a la naturaleza espía de esta para activar en el peatón el interés de saber de qué se trata aquello que suena (un poco conocido y desconocido a la vez). Tal como está compuesta la escucha de esta instalación, la experiencia del lugar se intensifica y transforma en los intersticios de la escucha de los peatones.

\section{FONOESFERAS: ESPACIOS DE RELACIÓN}

La instalación sonora es una práctica artística que se puede relacionar con el fonótopo, nombre que le ha dado Peter Sloterdijk a cierto tipo de esfera humana, porque relaciona al hombre con la voz, el sonido y la escucha. El fonótopo hace parte de lo que él ha señalado como las nueve islas humanas, consideradas "talleres de una creación de espacio complejo sin par. Surgen del ensamblaje de una plétora de tipos de espacio de cualidad específicamente humana, sin cuya apertura simultánea no sería imaginable la coexistencia de seres humanos con sus semejantes y con el resto de un todo común" $(2006,278)$. Son islas que representan distintos factores de la dimensión social de la humanidad, lo cual las liga íntimamente al contexto, aspecto que las instalaciones sonoras suelen interrogar.

El fonótopo es el único de los espacios antropógenos en el cual el sonido es el mensaje, pues lo que se escucha es la identidad misma del fonótopo, tal como lo es para muchas instalaciones sonoras. Es la razón por la cual su descubrimiento y comprensión se desarrolla en función de una escucha reiterativa. Tal como lo describe Sloterdijk, "hay que permanecer en ella para comprender cómo suena, y permanecer mucho tiempo para asimilarla en la propia existencia como una entonación que se va diluyendo en ella, como un inconsciente sonoro" $(2006,290)$.

Esa necesidad de permanencia es identificable en las instalaciones sonoras en la manera como se las construye, pues la estructura de acondicionamiento está pensada para que habite el sonido y asimismo los visitantes. Se trata de un acondicionamiento completamente artificial, porque se desafía la naturaleza efímera del sonido, de ahí el uso de parlantes, amplificadores y equipos de análisis acústico que hacen realidad que una obra sonora sea indefinidamente permanente. La permanencia del sonido es sinónimo de alojarlo en algún lugar para abrir entonces la posibilidad de experimentar la obra reiteradas veces y así descubrir su plasticidad sonora, pues es en el tiempo de inmersión indefinido que se puede valorar sus cualidades. 
La particularidad del fonótopo reside en que se trata de una experiencia acústica que identifica a un grupo de personas que se sienten moradoras de ese espacio, porque lo que suena les es común a todos: voces, músicas, paisajes sonoros. En la instalación sonora, este aspecto social se puede identificar igualmente en el deseo artístico de compartir con los demás ese universo sonoro. Por esta razón, Sloterdijk califica a la instalación artística como un espacio en el que "ser-en-el-mundo significa ser-en-la obra-del otro" (2006, 405). En Times Square, por ejemplo, se invita a escuchar un lugar imaginario que nace en gran medida del hallazgo que el artista ha hecho de escuchar ese lugar; su exploración consistió en buscar elementos estéticos en las cualidades acústicas y sonoras del lugar (de hecho, inaudibles para los demás). La obra es, por consiguiente, el resultado de esos hallazgos cuidadosamente seleccionados por su escucha. Aquí, en esta obra, el deseo propiamente es el de revelar y compartir esa escucha artística.

Por otro lado, el hecho mismo de tratarse de una práctica artística que se expone a un público ya lleva a compartir la experiencia con los otros, en especial porque para referirse a las experiencias sonoras se suele pasar por la palabra hablada o escrita, tal como sucedió con Times Square, que se creó un blog en internet.

Tanto el fonótopo como la instalación sonora son espacios autorreferentes, están subordinados a la naturaleza de una escucha aguda y relacional, pues cada oyente debe sumergirse en la escucha como modo de hacerse parte de ese lugar que se comparte con los demás por lo que se oye. En ambos casos, son territorios de una escucha que antes que nada es un acto de apertura, de conexión con el exterior, de darse y abrirse a mensajes sonoros de los otros y del entorno. Al fin de cuentas, escuchar es dejarse sumergir en otros universos, porque son interesantes para el oyente. Es un acto que busca complacerse y, por tanto, que busca tejer una relación armoniosa con ese exterior.

Por otro lado, ambas esferas están estructuradas por una escucha que es igualmente un acto en el que el oyente aprueba ser atravesado, penetrado por ese exterior que se manifiesta sonoramente. Por eso, según la teoría de Sloterdijk, la producción de estos espacios que se comparten manifiesta una necesidad social de estar conectados con los demás y lo otro, la cual se expresa por cuatro fenómenos de "intromisión": la incorporación, la invasión, la imbricación y la resonancia del lugar. Son procesos que están ligados a situaciones de encuentro en las que alguien o algo se infiltra en el propio espacio interior, evidenciando no solo un encuentro sino una situación de intercambio. Así define Sloterdijk (2002) cada uno de ellos:

- Incorporación: hacerse a un cuerpo para asumir una forma material.

- Invasión: penetrar un lugar por la fuerza.

- Imbricación: disposición de cosas que se entremezclan parcialmente.

- Implicación: asignar un rol en un caso dado.

- Resonancia física: aumento de la amplitud de oscilación cuando se excita en la vecindad de sus frecuencias propias.

Estos procesos son útiles para comprender las instalaciones sonoras en su relación sonido-espacio, porque ponen en evidencia la experiencia del espacio como preocupación artística. Ahora bien, esta relación no solo implica al espacio y al sonido mismo, sino al visitante, pues normalmente a este también se lo cuestiona, transforma, ocupa, redime o visibiliza. Dicho esto, las instalaciones sonoras bajo este análisis explicitan entonces su estructura fundamental: sonido, visitante, espacio. 
Times Square, por ejemplo, ejemplifica varios de estos fenómenos. El primero es el de la implicación, pues hay un deseo profundo del artista de irrumpir impredeciblemente en la vida cotidiana de los transeúntes. Times Square tiene asignado el rol de sorprender al transeúnte y cambiarle su recorrido ordinario. De manera general, Neuhaus en sus obras se enfoca en la exploración de las fronteras, por eso las instalaciones se entremezclan con el entorno y, al mismo tiempo, existen independientemente. Esa delimitación incierta entre creación y entorno sonoro las hace, por tanto, hacedoras del fenómeno de imbricación que tiene la particularidad de identificarse con las heterotopías de Foucault, también conocidas como espacios otros, porque se trata de lugares que por regla general tienden a yuxtaponer en un lugar real varios espacios que normalmente serían o deberían ser incompatibles o improbables (Foucault 2009, 24). Estos espacios surgen como desafíos para los espacios de vida y vinculan a la persona de otra manera a la realidad. Son lugares desviados de su uso, que abarcan algo más, por ejemplo, los caminos volcados por la imaginación de un niño. Por último, Times Square también presenta el fenómeno de la resonancia del lugar, pues las sonoridades se componen bajo el deseo de hacer resonar el lugar, amplificando sus cualidades acústicas y convirtiéndolas en objeto estético.

Otra manera de ejemplificar la implicación en la obra de Neuhaus es por medio de la instalación Identical Rooms (1989), expuesta en el Deichtorhallen Hamburg. Obra compuesta, como su nombre lo indica, de dos cuartos idénticos. En uno se escucha el sonido de un fluido, una sonoridad tenue aunque inmersiva; en el otro, una sonoridad densa, como si se tratara de pedazos de madera que se rozan. Lo que sucede en esta obra es que el volumen de los dos cuartos es percibido de manera muy distinta. La implicación de la obra se puede leer implícitamente en este comentario de Neuhaus:

\footnotetext{
Tengo que admitir que mi impulso podría haber sido silenciar a los adeptos de "Santo Tomás", esos que están tan convencidos de que la percepción del espacio pasa solo por la vista, ya que ellos creen que la idea de transformar un espacio únicamente por el sonido es simplemente retórica. Estuvo bien decir: "Si es retórica, ¿por qué esta habitación es más grande que la otra?". (1995, 3)
}

Si la implicación es asignar un rol en dado caso, el rol aquí es reivindicar lo sonoro con respecto a lo visual. Se trata de evidenciar que el sonido tiene esa capacidad de afectar la percepción, de "colorear" un espacio por sus cualidades, como si tratase de la luz que, según su color e intensidad, da la impresión de que el volumen del lugar es más amplio o más pequeño.

De hecho, esta obra ejemplifica otro tipo de experimentación con el sonido en el espacio: aquí se trata de exaltar la plasticidad del sonido y de explotar su capacidad de evocar imágenes capaces de trastocar la percepción espacial. Este tipo de exploración también la trabaja Robin Minard; aun así, hay dos diferencias remarcables. La primera radica en la manera como se relacionan las obras con el espacio. En sus instalaciones, no se esconden los elementos del acondicionamiento del espacio. Minard no solo expone los parlantes y sus cables, sino que los integra a la obra. Ellos se convierten en el elemento visual y tangible de la instalación. Por lo general, utiliza una cantidad considerable de pequeños parlantes y cables que suele disponer de tal manera que evocan formas naturales, como si se tratara de plantas o flores (figura 2). 


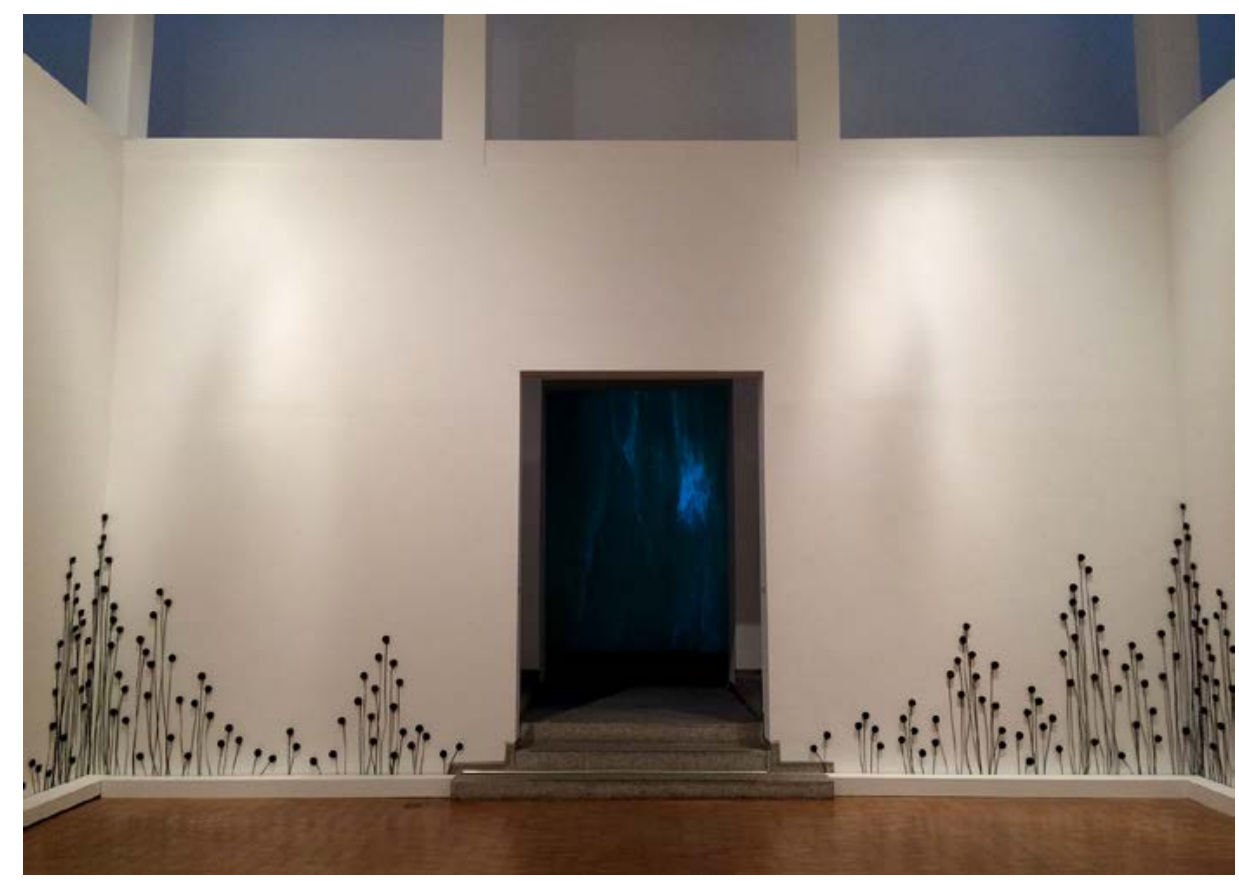

Figura 2. Silent Music (Séul), de Robin Minard.

Fuente: Robin Minard, Silent Music. Whanki Museum, Séul, 2014

http://www.robinminard.com/data/images/SilentMusic_RiverDream_Web.jpg

La segunda diferencia radica en la finalidad con la que explora la plasticidad de sus obras sonoras en el espacio, ya que Minard tiene un fuerte interés en integrar la práctica del diseño acústico a sus instalaciones. Sus obras intervienen espacios de vida con el fin de exaltar las cualidades acústicas y sociales del proyecto arquitectural del lugar intervenido. Así lo describe el artista:

En mi trabajo, la idea de instalación sonora ha significado algo muy específico: la integración del sonido en espacios públicos y, por tanto, la fusión de las obras, no solo con la arquitectura existente, sino también con las situaciones de todos los días y las funciones de los entornos reales. Los elementos visuales del trabajo han sido vinculados a consideraciones acústicas y a la amplificación de sonido en formas específicas. $(1996,77)$

La instalación Klangstille (1995) es un buen ejemplo de esto, ya que es creada con el objetivo de hacer que las condiciones de escucha de la biblioteca de la Universidad Técnica de Berlín sean diferentes pero efectivas para la función que cumple el lugar. Minard busca que la obra se armonice con la función social de lugar, a pesar de que en un principio parezca problemático crear un entorno sonoro confortable para que los estudiantes puedan consagrarse a su trabajo. Aquí Minard cuestiona la idea preconcebida de lo que es o debe ser el silencio en una biblioteca.

Según Minard: "Los sonidos de la instalación fueron diseñados para colorear ligeramente el silencio del espacio existente y para crear una atmósfera calmada, tranquila, propicia para la concentración y el estudio" $(1996,107)$. Por eso, las sonoridades de Klangstille son sutiles, casi silenciosas (como el título de la obra lo indica), capaces de filtrarse y mezclarse con las sonoridades del entorno (figura 3). 


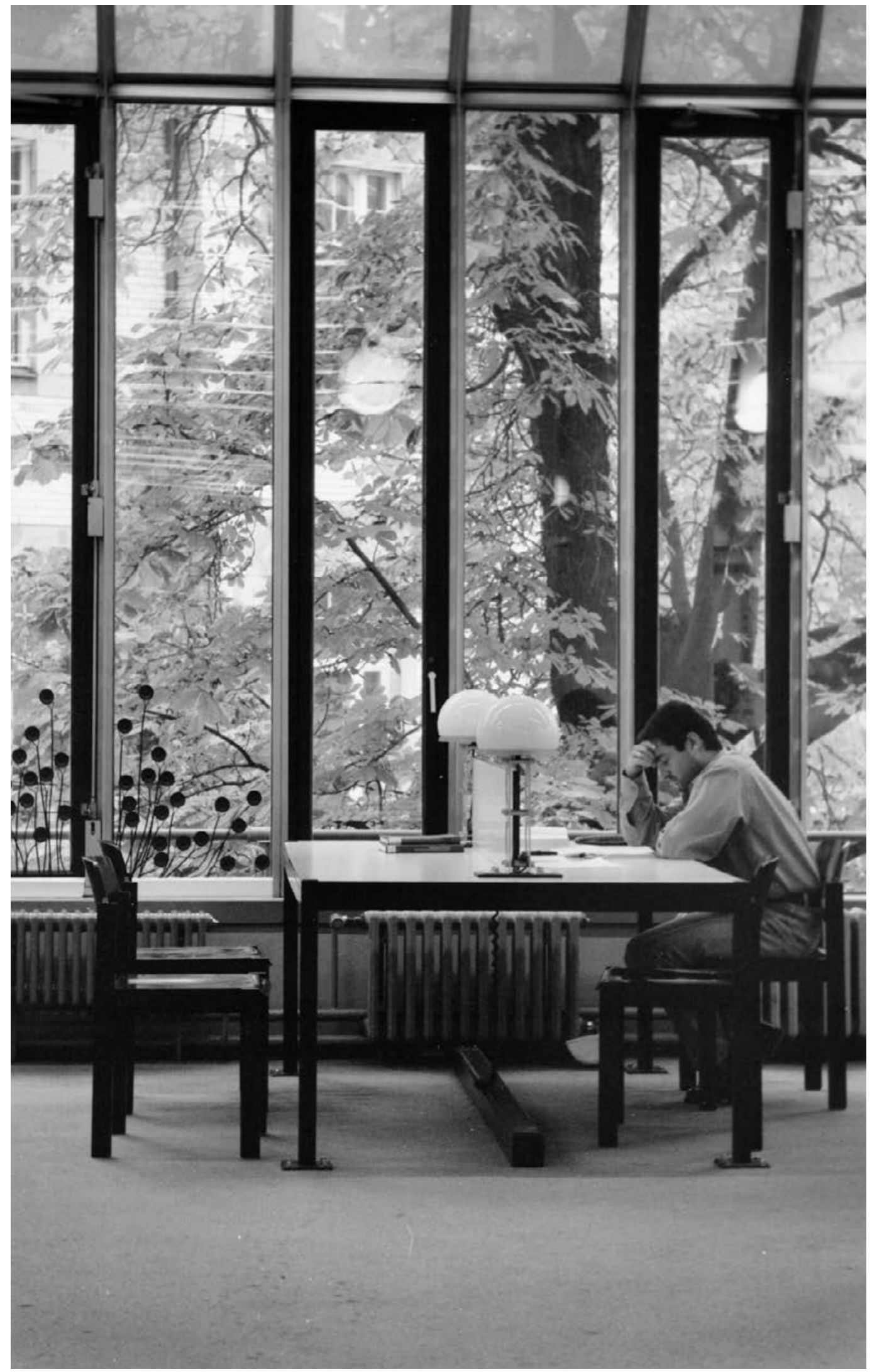

Figura 3: Klangstille (Berlin), Robin Minard, 1995

Fotógrafo : Niko Catania, Klangstille, sala de lectura de la Universidad Técnica de Berlin TU, 1995.

http://wwW.robinminard.com/minard.content.php?id=40\&sh= 
Klangstille manifiesta una actitud retadora en el artista, pues desea instalar una obra sonora en un espacio en el que el sonido, por lo general, no es bienvenido. También cuestiona el trabajo de la expresión con el sonido, ya que se abre la pregunta si es realmente necesario que siempre una obra deba ser escuchada de manera imponente y contundente. La respuesta se encuentra implícita en una obra como esta, ya que sus sonoridades manifiestan el interés por crear una situación "silenciosa" que pueda ser oída o escuchada (actividades distintas por la manera en que se le presta atención a lo que suena). Una representa una atención poco consciente de lo que sucede alrededor, la otra es realmente una escucha consciente y deseada). Independiente del grado de atención, lo importante es que la obra no es rechazada por el oyente. La prueba es que estando ella presente los estudiantes continúan con sus lecturas y estudios.

La plasticidad sonora de la obra radica, entonces, en tener unas cualidades inmersivas que se infiltran, ya no solo en el entorno de la biblioteca, sino en el espacio interior del lector. Son texturas sonoras relajantes que liberan a la mente, permiten concentrarse y que tienen esa capacidad de mimetizarse en un fondo sonoro "arrullador". Esta idea plástica de integrarse a su entorno también se ve reflejada en el acondicionamiento acústico y visual de la obra. Minard ubica pequeños parlantes a lo largo de las ventanas de la sala de lectura y del corredor cristalizado que lleva a la biblioteca. El modo en que lo hace da la impresión de que estos hacen parte del jardín que la rodea. Su ubicación, como bien lo señala Minard, también responde a una necesidad de articular el sonido en el espacio, ya que poner los parlantes en distintos lugares de la biblioteca garantiza que el sonido esté en todos lados, como si se tratase de un elemento más del paisaje sonoro del lugar. El propio artista ha denominado este proceso articulation of a space, y lo define de la siguiente manera: "Es la adición de la dimensión que falta en la arquitectura: el tiempo, o formulada al revés, la espacialización del sonido. El movimiento de los sonidos articula el espacio, modula su acústica, decorándolo con una escultura de sonido u ornamentos" (Schulz 2003, 55). El tiempo o la espacialización del sonido creado deja entrever una necesidad de que el sonido sea inmersivo, que sea capaz de circular en ese espacio como medio de intensificar la experiencia del estar contenido en ese lugar. El tiempo y el modo en el que el sonido creado viaja, atraviesa, se refleja e imprime sus cualidades en el espacio escogido, es una manifestación clara del deseo artístico de imbricar y marcar un territorio.

A través de Klangstille, se podría deducir que el trabajo de Minard está relacionado también con el fenómeno de la incorporación que implica "hacerse a un cuerpo para asumir una forma material." Las obras de Minard siempre toman formas orgánicas con la finalidad de integrarse estéticamente a los lugares de presentación. De hecho, es en sí un distintivo de sus instalaciones. Estas formas materializan su obra sonora y también revelan su fascinación por la naturaleza. Es por la forma visual, común a la gran mayoría de personas, que el artista intuye que al espectador le será familiar y "positiva" la intervención estética de su espacio de vida. La imbricación, implicación e, incluso, resonancia física también definen la relación de Klangstille con el oyente y el espacio. Es cuestión de citarlo para entenderlo brevemente: “Debemos concebir un arte que tenga en cuenta el entorno, el cual entra en relación y diálogo con el espacio que ocupa. Esto es para el artista ser consciente de las necesidades del entorno para que el que está diseñado el trabajo, y para tomar una acción positiva" (Schulz 2003, 53). Sus obras expresan un deseo por fusionar el arte con la vida, de transformar artísticamente esos espacios vitales del hombre en un mínimo grado, sin que estos cambien sus funciones cotidianas. Se trata al fin de cuentas de intensificar la experiencia de esos lugares. 
Queda por relacionar el último fenómeno de imbricación del que habla Sloterdijk con la instalación sonora. Se trata de la invasión, la cual se caracteriza por "penetrar un lugar por la fuerza." Es interesante esta relación del sonido con el oyente y el espacio, porque, a diferencia de las otras maneras de relacionarse con el exterior: imbricación, implicación, resonancia física, incorporación, esta demuestra la capacidad que tiene el sonido de imponerse. Este proceso no busca armonizar y atraer al oyente, aun así, sí busca atravesarlo. Tal como lo señala Sloterdijk, este tipo de relación pone en evidencia ese deseo humano por descubrir el mundo de otros; intrusos que muchas veces aportan destrucción pero que al final de cuentas enriquecen, ya que se despliega un proceso de reafirmación de lo que se es.

La obra que puede ejemplificar con gran claridad este fenómeno es Recursivity, de Céleste Boursier-Mougenot, instalada en la Chapelle de la Visitation, en la ciudad de Périgueux en 1997. La obra se concentra visualmente sobre uno de los bancos de la iglesia, el cual se desplaza lentamente gracias a tornos motorizados que se accionan por sensores de movimiento. Estos se activan en función de la intensidad sonora de lo que está ocurriendo afuera de la capilla: paso de peatones, ruido del entorno, pitos de carros, etc. Bajo este sistema de interactividad, el banco se mueve de manera imprevisible para el visitante de la obra, porque lo que sucede al interior de la capilla está únicamente asociado al movimiento del banco. El ruido que este produce es amplificado por micrófonos que al mismo tiempo retroalimentan lo que está sucediendo, magnificando entonces el poder desestabilizante del ruido que se produce. Como los visitantes no saben qué es lo que realmente activa el desplazamiento del banco, ellos creen que la silla chilla por su presencia, sus voces y movimientos, provocando muchas veces la petrificación de sus cuerpos para así evitar que siga evolucionando el ruido.

Esta obra juega con el poder que tiene el sonido en tanto ruido, ya que este tiene la capacidad de paralizar y de atravesar el cuerpo del escucha sin que este le haya dado la bienvenida. Boursier-Mougenot también juega con otra particularidad del sonido, y es su connotación social. No es gratuito que la instalación tenga lugar en una capilla, pues el ruido en ese contexto es inapropiado y rechazado. Normalmente, estos lugares son silenciosos con el fin de procurarse un ambiente que facilite la reflexión, la escucha de la voz interna. En cierta medida, son silenciosos para que cada persona pueda permanecer encerrada en su espacio interior, pues la reflexión y meditación están asociadas a habitáculos individuales. De ahí que los murmullos o sonidos corporales de los otros se escuchen con facilidad y no sean bien vistos. ¿Qué se podría decir del chirrido abrumador de una silla que se ha desplazado por la indelicadeza de un visitante-extraño que ha entrado en la capilla?

Tal como lo propone Christophe Kihm, en esta obra hay una trampa y es la silla.

Me siento en la silla y de inmediato soy atrapado por mi propia imagen, y la trampa social se cierra sobre mí. Cuanto más lucho, más produzco el sonido, y más veremos el animal social que soy yo derrumbarse. Es una muy buena trampa, ya que se cierra inmediatamente sobre su presa. (Kihm 2008, 50)

La trampa aquí es una manera muy particular de sumergir imperativamente al oyente por medio de un ruido que se impone. Boursier-Mougenot vuelve explícito el cuestionamiento en torno al orden social del ruido en una iglesia al amplificar el ruido de la silla y llevarlo a una escala de volumen exagerada. Por esta razón, el artista ya no solo cuestiona sino que ridiculiza 
el ruido en ese contexto. La estrategia no solo radica en eso, sino en poner en el centro del escenario de la instalación la silla. A su alrededor se distinguen otros bancos alrededor de la escena que invitan a otros visitantes a sentarse y asistir a ese acto denunciador en el cual algún otro visitante se ve implicado. En el fondo, se trata de confrontar al visitante a distintos niveles, con su corporalidad, con el otro, y con el orden social al que pertenece el ruido.

Boursier-Mougenot busca constantemente en sus instalaciones activar la escucha del oyente y para eso suele recurrir a lo impredecible y a la sorpresa. De ahí que manifieste que "sorprender a la gente y darles placer es lo más subversivo que un artista puede hacer" $(2002$, 54). El placer en Recursivity se encuentra en la ridiculización de la situación, que a final de cuentas provoca la risa de una gran parte de los visitantes, o por vergüenza, timidez, diversión, o porque finalmente han comprendido el comportamiento aleatorio de la silla y su ruido que nada tiene que ver con ellos; el ruido aquí deja de ser objeto de temor y se convierte en objeto de burla.

Esta obra es interesante, entre muchas razones, porque manifiesta otra manera en que los artistas exploran la relación sonido-espacio, y es precisamente la de cuestionar los códigos y símbolos que se construyen en los espacios sociales al rededor del sonido, que incluye los espacios más sagrados hasta los más banales. Esa relación está vinculada, por consiguiente, a situaciones en las que el sonido o su ausencia tiene un rol protagónico, ya que expresa maneras de comportarse en un espacio determinado. En esta relación, el cuerpo del oyente adquiere mayor protagonismo por ser o haber sido el productor de esos sonidos que se interrogan.

Las instalaciones sonoras son comprendidas como manifestaciones de un pensamiento espacial que cuestiona con certeza un aspecto de la dimensión social del hombre: su relación con lo que él produce sonoramente con su voz y su cuerpo en un espacio de vida.

Esta práctica también revela la necesidad de construir un pensamiento sonoro por medio de la experimentación misma con el sonido. Esto implica la creación de situaciones en las que se experimentan maneras de modelar la escucha y de construir moradas acústicas, de ahí la importancia que adquiere el contexto como medio de lineamiento para materializar esos espacios sonoros.

Las instalaciones sonoras son territorios de escucha que se impregnan distintamente de la estructura misma de la audición. Son relacionales, indagadoras, depredadoras, protectoras, autocomplacientes o defensivas, duales, posesivas, tal como lo es la audición.

El aspecto inmersivo de esta práctica responde, igualmente, a esa necesidad de que la obra sonora sea, antes que nada, una experiencia que se pueda compartir, pues sin esto es difícil de interrogar. Por esto, Sloterdijk indica que la instalación se manifiesta así, "como el instrumento más poderoso del arte contemporáneo para colocar en el espacio de observación situaciones sumergentes como un todo" $(2006,403)$.

Asimismo, esta práctica confronta el cuerpo del oyente con la mirada de los otros, pues la acción que se desencadena tras la escucha de la obra interroga como primera medida la acción de este. Es el caso de Times Square, pues sumergirse en la obra, ya dando vueltas entorno al pasaje peatonal, ya acostándose sobre las rendijas para escuchar atentamente, interroga a los demás sobre qué hay en ese lugar.

La instalación sonora también expresa una preocupación por interrogar lo visual. De ahí que se tejan relaciones anodinas, impredecibles o chocantes entre el espacio arquitectónico y el sonido. La sorpresa de esa conexión inédita es la que desencadena ese cuestionamiento, que, por cierto, no excluye otros sentidos como el tacto. 
Por último, la instalación sonora refleja una fascinación del hombre por los espacios que él construye con sus propias herramientas y estrategias de acondicionamiento artificiales, ya que se sumerge a los demás en sus propias utopías. Así lo manifiestan desde tiempos antiguos filósofos como Sócrates: "Una pintura, querido Fedro, solo cubre una superficie, la de un cuadro o un muro... pero un templo, cuando se entra en él, o incluso el interior de ese templo, constituye para nosotros una especie de grandeza plena, en la que vivimos... ¡Estamos, nos movemos, vivimos en la obra de un ser humano!... Nos sentimos impresionados y sobrepujados por las condiciones que él ha elegido. No podemos sustraernos a él" (Sloterdijk 2006, 404). Esta fascinación es aún más fehaciente en la exploración con el sonido porque este siempre pasa por la mediación y el acondicionamiento para ser explorado artísticamente y socialmente; para modelar más cuidadosamente lo que desea escuchar y quiere dar a escuchar en tanto espacios vitales de inmersión acústica.

\section{NOTAS}

1. Traducciones realizadas por Carolina Ortiz Cerón.

\section{REFERENCIAS}

Bosseur, Jean-Yves. 1992. Le sonore et e visuel: intersections musique-arts plastiques aujourd'hui. París: Distributed Art Pub Inc.

Boursier-Mougenot, Céleste. 2002. “Entrevista con Camille Labro". Magazin Beaux-arts (213): 54.

— 2008. États seconds. Arlès: Analogues.

Foucault, Michel. 2009. Le corps utopique, les hétérotopies. París: Nouvelles Éditions Lignes.

Kihm, Christophe. 2008. "Ajustements: entretien de Christophe Kihm avec François Quintin". En États seconds, de Céleste Boursier-Mougenot, 22-75. Arles: Analogues.

"Klangstille". 1995. "Klangstille" (sala de lectura de la Universidad Técnica de Berlín TU). 1995. Niko Catania. http://www.robinminard.com/minard.content.php?id=40\&sh=0Minard, Robin. 1996. Sound Installation Art. Graz: Editeur Institut für Elektronische Musik.

Neuhaus, Max. 1995. Evoquer l'auditif. Niza: Editorial Charta/Museo de Arte Contemporáneo Villa Arson.

- 1998. "Max Neuhaus from a conversation with Michael Tarantino". Two Passages. http://www. maxneuhaus.info/soundworks/vectors/passage/twopassages/

- 1999. "Mysterious Noises on 46th Street | Times Square New York City". http://adam.curry.com/ art/1376408041_QPUL9BYF.html.

Regnauld, Hervé. 2011. "Le concept de tout est une forme: la pensée spatiale de Peter Sloterdijk". EspacesTemps.net. https://www.espacestemps.net/articles/le-concept-de-tout-est-une-forme-lapensee-spatiale-de-peter-sloterdijk/

Roberts, Lynda. 2017. "NYC, Listening to Max Neuhaus's Times Square". Flickr. https://www.flickr.com/ photos/publicassembly/37410284151 
Schulz, Bernd. 2003. "Form and Function in the Sound art of Robin Minard". En Silent Music: Between Sound art and Acoustic Design, de Robin Minard. Heidelberg: Kehrer Verlag.

Sloterdijk, Peter. 1987. Critique de la raison cynique. París: Christian Bourgois.

— 2001. Extrañamiento del mundo. Valencia: Pre-Textos.

- 2002. Sphères I, Bulles. París: Hachette.

- 2006. Esferas III. Madrid: Siruela.

Szendy, Peter. 2001. Écoute: une histoire de nos oreilles. París: Minuit.

- 2015. En lo profundo de un oído: una estética de la escucha. Santiago de Chile: Metales Pesados.

Vásquez Rocca, Adolfo. 2008. Peter Sloterdijk: esferas, helada cósmica y políticas de climatización. Valencia: Institució Alfons el Magnànim/Diputación de Valencia.

Wuillème, Tanguy. 2002. "Peter Szendy, Écoute. Une histoire de nos oreilles, précédé de Ascoltando par Jean-Luc Nancy", Questions de communication. http://journals.openedition.org/ questionsdecommunication/6532. 